\title{
Sex Differences in the Psychophysical Response to Contact Heat in Moderate Cognitive Impairment Alzheimer's Disease: A Cross-Sectional Brief Report
}

\author{
Ronald L. Cowan ${ }^{\mathrm{a}, \mathrm{c}, \mathrm{d}, \mathrm{e}}$, Paul A. Beach ${ }^{\mathrm{b}}$, Sebastian W. Atalla ${ }^{\mathrm{c}, \mathrm{f}}$, Mary S. Dietrich $^{\mathrm{c}, \mathrm{d}, \mathrm{e}, \mathrm{f}}$, \\ Stephen P. Bruehle, Jie Deng ${ }^{f}$, Jinjiao Wang ${ }^{f}$, Paul A. Newhouse ${ }^{\text {d,e,g }}$, John C. Gore ${ }^{a, e}$ \\ and Todd B. Monroe ${ }^{\mathrm{a}, \mathrm{c}, \mathrm{d}, \mathrm{e}, \mathrm{f}, *}$ \\ ${ }^{a}$ Vanderbilt University Medical Center Institute of Imaging Science, Nashville, TN, USA \\ ${ }^{\mathrm{b}}$ Emory University School of Medicine Department of Neurology, Atlanta, GA, USA \\ ${ }^{\mathrm{c}}$ Vanderbilt University Medical Center Psychiatric Neuroimaging Program, Nashville, TN, USA \\ ${ }^{\mathrm{d}}$ Vanderbilt University Department of Psychiatry and Behavioral Sciences, Nashville, TN, USA \\ ${ }^{\mathrm{e}}$ Vanderbilt University Medical Center, Nashville, TN, USA \\ ${ }^{\mathrm{f}}$ Vanderbilt University School of Nursing, Nashville, TN, USA \\ ${ }^{\mathrm{g}}$ Vanderbilt Center for Cognitive Medicine, Nashville, TN, USA
}

Accepted 21 August 2017

\begin{abstract}
.
Background: People with Alzheimer's disease (AD) report pain less frequently and receive less pain medication than people without AD. Recent studies have begun to elucidate how pain may be altered in those with AD. However, potential sex differences in pain responsiveness have never been explored in these patients. It is unclear whether sex differences found in prior studies of healthy young and older individuals extend to people with AD.

Objective: The purpose of this study was to examine sex differences in the psychophysical response to experimental thermal pain in people with $\mathrm{AD}$.

Methods: Cross-sectional analysis of 14 male and 14 female age-matched ( $\geq 65$ years of age, median $=74$ ) and AD severitymatched (Mini-Mental State Exam score <24, median =16) communicative people who completed thermal psychophysics. Results: There was a statistically significant main effect of sex for both temperature and unpleasantness ratings that persisted after controlling for average and current pain (mixed-effects general liner model: temperature: $p=0.004$, unpleasantness: $p<0.001)$. Females reported sensing mild pain and moderate pain percepts at markedly lower temperatures than did males (mild: Cohen's $d=0.72, p=0.051$, moderate: Cohen's $d=0.80, p=0.036$ ). By contrast, males rated mild and moderate thermal pain stimuli as more unpleasant than did females (mild: Cohen's $d=0.80, p=0.072$, moderate: Cohen's $d=1.32, p=0.006$ ). There were no statistically significant correlations of temperature with perceived unpleasantness for mild or moderate pain $\left(r_{s}=0.29\right.$ and $r_{s}=0.20$ respectively, $\left.p>0.05\right)$.

Conclusions: Results suggest experimental pain-related sex differences persist in older adults with AD in a different manner than those previously demonstrated in cognitively intact older adults. These findings could potentially aid in developing targeted pain management approaches in this vulnerable population. Further studies are warranted to replicate the findings from this pilot work.
\end{abstract}

Keywords: Alzheimer's disease, dementia, pain, pain threshold, perception, sex differences

*Correspondence to: Todd B. Monroe, PhD, RN-BC, FGSA, FAAN, Vanderbilt University, Schools of Nursing and Medicine, 46121 st Avenue S, 419 Godchaux Hall, Nashville, TN 37240,
USA. Tel.: +1 615322 1719; E-mail: todd.b.monroe@ vanderbilt. edu. 


\section{INTRODUCTION}

Alzheimer's disease (AD) affects an estimated 40 to 50 million older adults worldwide [1], and approximately $50 \%$ of older adults with AD consistently report pain [2]. Unfortunately, adults with AD may have suboptimal pain management [3]. Potential vehicles of inappropriate pain management in AD include impaired pain reports leading to subsequent under-prescription of analgesics [4]. Indeed, the likelihood of significant difficulties in verbal communication is far greater when compared to a healthy adult. This vulnerability to inappropriate pain management in people with $\mathrm{AD}$ is amplified by recent studies suggesting aspects of heightened pain sensitivity [5], increased verbal reports of clinical pain [3], greater degree of pain behavior [6-8], increased pain processing [9], and altered functional connectivity in pain processing regions $[10,11]$. However, factors affecting pain perception in patients with $\mathrm{AD}$ may exist beyond the effects of the disease itself.

There are numerous studies examining painrelated sex differences in healthy young adults and to a lesser extent healthy older adults. Current literature suggests that relative to cognitively intact males, cognitively intact females have an increased incidence of clinical and experimental pain (reviewed in [12]). Studies of otherwise healthy older adults have found that females have increased osteoarthritic pain sensitivity and increased experimental temporal summation to heat stimuli $[13,14]$. It is unclear how these findings translate to pain perception in older adults with AD.

Decoding altered pain perception in people with $\mathrm{AD}$ is important not only for alleviating pain symptoms, but also in identification of the underlying source. Improved understanding of pain-related sex differences in communicative adults with AD may thus facilitate development of targeted assessment and treatment in this vulnerable population. Indeed, understanding sex differences between males and females with $\mathrm{AD}$ is particularly prudent given that sex is an important epidemiologic factor in AD prevalence (reviewed by [15]) and analgesic use in $\mathrm{AD}$ patients [5].

One method to elucidate potential sex differences in pain perception in people with $\mathrm{AD}$ is by examining the relationship between physical stimuli and resulting mental events, i.e., psychophysical responses (stimulus detection, pain threshold, and tolerance), to standardized evoked pain stimuli, such as thermal, mechanical, or electrical stimuli. The overall goal of this study was to examine whether there are sex differences in pain-related psychophysics in AD. To accomplish this goal, we performed a cross-sectional examination of the psychophysical responses to thermal pain in a group of a sex-, age-, and $\mathrm{AD}$ severity-matched sample of communicative older adults with moderate cognitive impairment. We posited that sex differences in pain psychophysics found in cognitively healthy adults would persist in those with AD. More specifically, we predicted that, relative to males with $\mathrm{AD}$, females with $\mathrm{AD}$ would exhibit lower pain thresholds and report greater unpleasantness during contact thermode-related perceptions of "warmth," "mild pain," and "moderate pain."

\section{METHODS}

\section{Design}

The current study was cross-sectional in nature. The Vanderbilt Ethics Committee and the Vanderbilt University Institutional Review Board (IRB no. 111290) approved this study.

\section{Sample and setting}

The current study sample of 14 males and 14 females ( $\geq 65$ years of age) was a subset of participants from a larger psychophysical study $(n=80)$ examining pain in mild to moderate $\mathrm{AD}$ relative to cognitively normal people [10]. Because the aim of the current study was to examine sex differences in moderate cognitive impairment in $\mathrm{AD}$, only subjects with Folstein Mini-Mental State Exam (MMSE) [16] scores $<24$ were included from the sample of 80 , resulting in a final sample of $28(14=$ female $)$. Subject recruitment occurred in the greater Nashville, Tennessee area (Fig. 1). A primary care physician diagnosed each subject with AD and study personnel confirmed an AD diagnostic work-up in the medical record (e.g., structural neuroimaging, neuropsychiatric evaluation, genetic testing, and tests to rule out reversible causes of memory loss). This confirmatory process was developed using the National Institute of Neurological and Communicative Disorders and Stroke and the Disease and Related Disorders Association (NINCDS-ADRDA) criteria for probable AD [17]. Inclusion criteria included English-speaking adults $\geq 65$ years of age, who could provide a verbal pain rating, and had no consumption of analgesic medication within $24 \mathrm{~h}$ of testing. Trained 


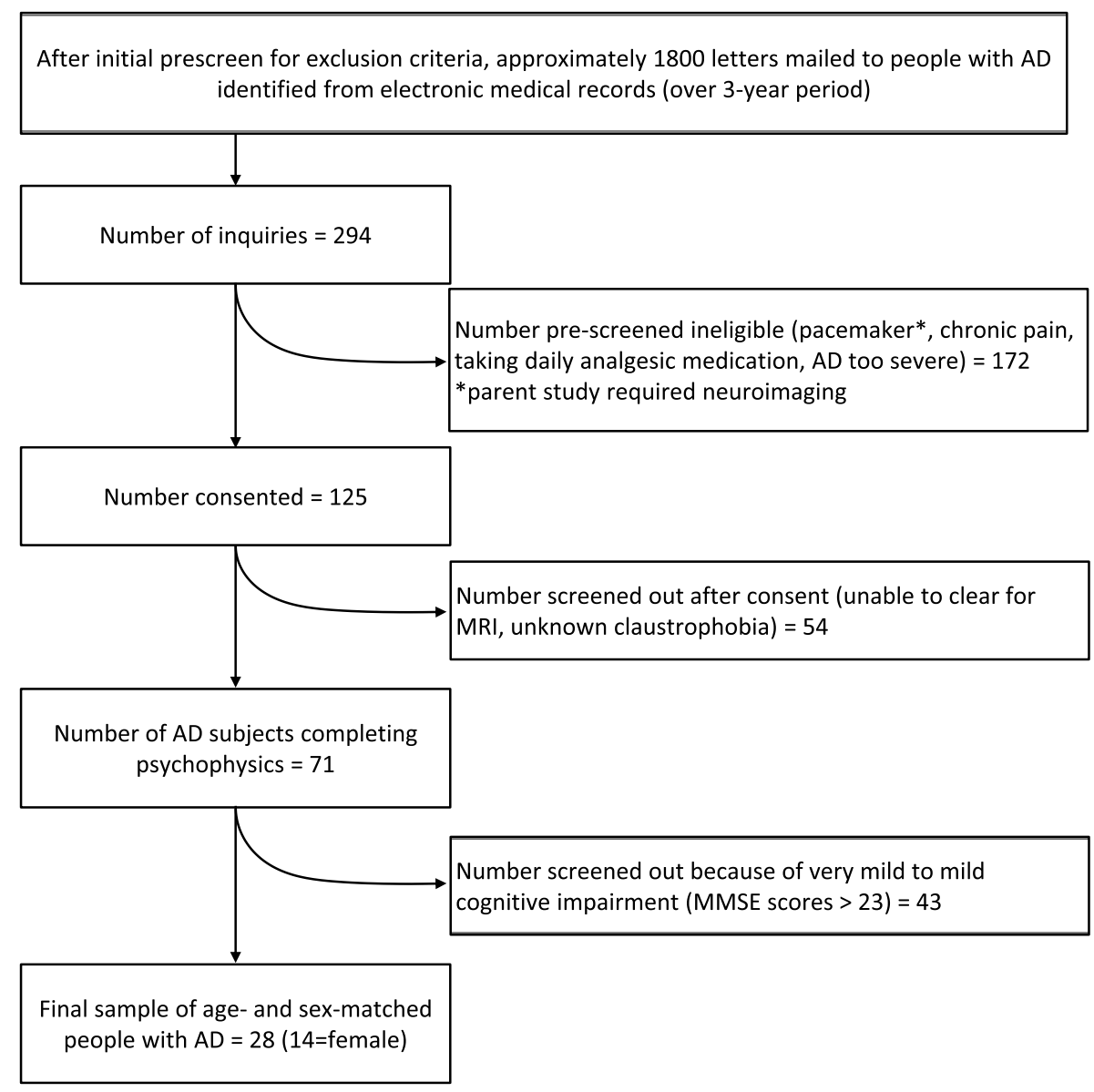

Fig. 1. Study sample flow chart.

research assistants determined communicative ability by assessing responsiveness during questionnaires, and by the subject's ability to answer spatially and temporally oriented questions [18].

Subjects were excluded for current or average pain requiring regular use of opioid or non-narcotic pain medications and a history of stroke with residual sensory deficits, cancer, upper extremity neuropathy, diabetes, rheumatoid arthritis, schizophrenia, bipolar disorder, current or recent substance use disorders, or Parkinson's disease. With their legal surrogate present, participants were instructed to avoid taking any pain medication (opioid or non-opioid) for at least $24 \mathrm{~h}$ prior to data collection.

\section{Procedures and data collection}

After obtaining informed assent and legal caregiver consent, demographics, pain, depressive symptomology, anxiety, and thermal psychophysics were assessed. To facilitate increased understanding, a trained research assistant verbally administered questionnaires to all subjects.

\section{Psychophysical assessment}

Psychophysical percepts were elicited through thermal stimulation applied to the palmar thenar eminence of the right hand. Using the 'Method of Limits' program on the Medoc PATHWAYS Model CHEPS Pain and Sensory Evaluation System [19], participants were instructed to identify temperatures they perceived as "warmth," "mild pain," and "moderate pain." The 'Method of Limits' program employed by the PATHWAYS system consists of temperature administration at a ramp-rate of $1^{\circ} \mathrm{C}$ per second. Temperatures increased until the participant indicated that the perceived heat had reached one of the three percepts. The chosen ramp rate allows a cognitively impaired subject ample time to 
respond to perceptual prompts, while minimizing the chance of overshooting. After each thermal stimulus application, the unpleasantness associated with each percept was assessed using a 0-20 unpleasantness scale $(0=$ neutral and $20=$ extreme unpleasantness). The 0-20 unpleasantness measure has been successfully used in people with dementia [9]. Instructions were kept brief to facilitate understanding by participants with $\mathrm{AD}$, and repetition was used to cement understanding of the task. After three trials of each condition average reported temperature and unpleasantness scores were recorded.

\section{Global cognitive function}

The MMSE [16] was used to assess severity of cognitive impairment. MMSE scores range from 0 (worst cognitive status) to 30 (best cognitive status), with a single cut-off score of 23 indicating "likely dementia" [16]. Subjects in the current study were selected from the parent study because they scored 23 or less on the MMSE.

\section{Depression and anxiety}

Anxiety and depression levels were assessed because these measures may be increased in $\mathrm{AD}$ compared to controls, may differ between males and females, and can affect pain perception [20]. Depressive symptoms were measured using the Geriatric Depression Scale Short Form (GDS-15) [21]. Scores range from 0 to 15 , where a score $\geq 6$ suggests possible depression [22]. Anxiety was measured using the Spielberger State-Trait Anxiety Inventory (STAI) [23]. Scores range from 20 to 80 with higher scores indicating greater anxiety. Among community dwelling older adults with and without dementia, the GDS- 15 was $71.8 \%$ sensitive and $78.2 \%$ specific for detecting depression [22]. The psychometric properties of the STAI in detecting anxiety symptoms in $\mathrm{AD}$ when administered as an interview have yet to be determined.

\section{Clinical pain}

Clinical pain (current and average daily levels) was measured using the Brief Pain Inventory Short Form (BPI-SF) [24]. The BPI-SF measures multiple dimensions of pain and consists of nine questions including pain location and pain intensity as well as pain interference with daily life (e.g., sleep, mood, etc.). The BPI-SF was administered verbally to par- ticipants in the parent study as a structured pain interview. For this analysis, questions 5 and 6 on the BPI-SF were included because these two questions specifically address current and average pain on a 0-10 numeric rating scale. Structured pain interviews using the 0-10 scale in nursing home residents with and without cognitive impairment have demonstrated 1 -month stability coefficients ranging from 0.56 to $0.72[25]$.

\section{Data analysis}

Data analyses were conducted using SPSS Version 23. Analyses of sex differences in subject characteristics and demographics were conducted using Chi-Square tests (nominal or ordinal data), independent samples $t$-tests (normally distributed continuous data), or Mann-Whitney tests (skewed continuous data). Mixed-effects general linear modeling was used to test main effects of sex on psychophysical outcomes (i.e., temperature and unpleasantness), with average and current clinical pain (BPI-SF) scores entered as covariates of non-interest. Post-hoc tests of sex differences at each percept threshold level (i.e., warmth, mild pain, and moderate pain) involved Mann-Whitney testing. A two-tailed $p<0.05$ determined statistical significance.

\section{RESULTS}

\section{Sample characteristics}

Sample characteristics are summarized in Table 1. Median age was 74 years (IQR: 70-80). The sample was primarily Caucasian (78.6\%), with a median MMSE score of 16 (IQR: 12-20). No statistically significant differences were found between males and females with respect to depression and anxiety scores $(p>0.05)$. In general, low BPI-SF scores were reported, though levels were higher in females than males (average pain $p=0.016$; pain right now $p=0.036$ ).

\section{Psychophysics}

Summaries of thermal psychophysical outcomes by sex are shown in Table 2 . There were statistically significant main effects of sex for both temperature and unpleasantness ratings that persisted after controlling for average and current pain (mixed-effects general liner model: temperature: $\mathrm{F}_{(\mathrm{df}}={ }_{1,63)}=8.98, p=0.004$, unpleasantness: 
Table 1

Demographic and clinical summaries by sex

\begin{tabular}{|c|c|c|c|c|}
\hline & $\begin{array}{c}\text { Total } \\
(\mathrm{N}=28)\end{array}$ & $\begin{array}{l}\text { Female } \\
(n=14)\end{array}$ & $\begin{array}{c}\text { Male } \\
(n=14)\end{array}$ & $p$-value \\
\hline & Median [IQR] & Median [IQR] & Median [IQR] & \\
\hline Age & $74.0[70-80]$ & $75.5[71-81]$ & $73.0[67-81]$ & 0.606 \\
\hline Race & $\mathrm{n}(\%)$ & $\mathrm{n}(\%)$ & $\mathrm{n}(\%)$ & 0.357 \\
\hline Caucasian & $22(78.6)$ & $10(71.4)$ & $12(85.7)$ & \\
\hline African-American & $6(21.4)$ & $4(28.6)$ & $2(14.3)$ & \\
\hline Marital Status & & & & 0.082 \\
\hline Married & $14(51.9)$ & $5(35.7)$ & $9(69.2)$ & \\
\hline Not Married & $13(48.1)$ & $9(64.3)$ & $4(30.8)$ & \\
\hline Standardized measures & Median [IQR] & Median [IQR] & Median [IQR] & \\
\hline Body mass index & $26.3[22-28]$ & $24.5[21-28]$ & $26.5[22-28]$ & 0.703 \\
\hline MMSE score ${ }^{1}$ & $16.0[12-20]$ & $15.5[11-22]$ & $16.0[11-19]$ & 0.522 \\
\hline BPI-SF average pain ${ }^{2}$ & $0.0[0-0]$ & $0.0[0-5]$ & $0.0[0-0]$ & 0.016 \\
\hline BPI-SF pain right now ${ }^{2}$ & $0.0[0-0]$ & $0.0[0-2]$ & $0.0[0-0]$ & 0.035 \\
\hline GDS-SF score ${ }^{3}$ & $3.0[1-5]$ & $2.5[0-5]$ & $3.0[1-6]$ & 0.714 \\
\hline STAI state score ${ }^{4}$ & $47.5[45-52]$ & $48.0[46-50]$ & $46.0[45-52]$ & 0.692 \\
\hline STAI trait score ${ }^{4}$ & $47.0[43-50]$ & $47.0[43-50]$ & $47.0[44-49]$ & 0.827 \\
\hline
\end{tabular}

${ }^{1}$ MMSE, Folstein Mini-Mental State Examination. ${ }^{2}$ BPI-SF, Brief Pain Inventory Short Form (range $=0-10$; $0=$ no pain, $10=$ most pain). ${ }^{3}$ GDS-SF, Geriatric Depression Scale Short Form (range; $0=$ no indication of depression, $15=$ high possibility of depression). ${ }^{4}$ STAI, Spielberger State or Trait Anxiety Inventory (range; $20=$ indicates increased anxiety, $80=$ indicates least amount of anxiety).

Table 2

Summary of psychophysics of temperature thresholds necessary to produce warmth, mild pain, or moderate pain and unpleasantness ratings at each condition ( $\mathrm{N}=28 ; n=14$ male; $n=14$ female)

\begin{tabular}{lcccccc}
\hline Variables & Min & Max & Median & IQR & $p$-value $^{\mathrm{a}}$ & $\begin{array}{c}\text { Effect } \\
\text { Size }^{b}\end{array}$ \\
\hline $\begin{array}{l}\text { Temperature } \\
\text { Warmth }\end{array}$ & & & & & & \\
$\quad$ Males & 33 & 38 & 34.0 & $33-36$ & 0.623 & 0.20 \\
$\quad$ Females & 32 & 39 & 34.5 & $32-36$ & & \\
Mild Pain & & & & & & \\
$\quad$ Males & 35 & 44 & 41.0 & $35-43$ & 0.051 & 0.72 \\
$\quad$ Females & 33 & 44 & 37.0 & $35-40$ & & \\
Moderate Pain & & & & & & \\
$\quad$ Males & 36 & 50 & 44.0 & $41-46$ & $\mathbf{0 . 0 3 6}$ & $\mathbf{0 . 8 0}$ \\
$\quad$ Females & 36 & 47 & 39.0 & $37-44$ & & \\
$\quad \begin{array}{l}\text { Unpleasantness } \\
\text { Warmth }\end{array}$ & & & & & & \\
$\quad$ Males & 0 & 6 & 0.0 & $0-2$ & 0.688 & 0.15 \\
$\quad$ Females & 0 & 4 & 0.0 & $0-2$ & & \\
Mild Pain & & & & & & \\
$\quad$ Males & 0 & 11 & 4.5 & $3-7$ & 0.072 & 0.82 \\
$\quad$ Females & 0 & 11 & 1.0 & $0-5$ & & \\
Moderate Pain & & & & & & \\
$\quad \begin{array}{l}\text { Males } \\
\quad \text { Females }\end{array}$ & 4 & 13 & 7.5 & $5-13$ & $\mathbf{0 . 0 0 6}$ & $\mathbf{1 . 3 2}$ \\
\hline
\end{tabular}

Mixed-effects general linear modeling used to test for overall differences between females and males controlling for reports of average pain and pain now. Main effects of gender. Temperature $p=0.004$, Unpleasantness: $p=0.001$. ${ }^{\mathrm{a}} p$-value derived from post-hoc Mann-Whitney tests. ${ }^{\mathrm{b}}$ Cohen's d effect size index.

$\left.\left.\mathrm{F}_{(\mathrm{df}}=1,76\right)=13.27, p<0.001\right)$. Follow-up analyses at each percept (warmth, mild pain, and moderate pain) revealed that the strongest effects of sex were at the mild and moderate pain levels for both stimulus temperature and perceived unpleasantness. Effect sizes by sex increased dramatically between the warmth and mild pain percepts, accounting for much of the main effect findings. Females reported sensing mild pain and moderate pain percepts at markedly lower temperatures than did males (mild: Cohen's $d=0.72$, $p=0.051$, moderate: Cohen's $d=0.80, p=0.036$ ). To the contrary, males rated mild and moderate thermal pain stimuli as more unpleasant than did females (mild: Cohen's $d=0.80, p=0.072$, moderate: Cohen's $d=1.32, p=0.006$ ). There were no statistically significant correlations of temperature with perceived unpleasantness for mild or moderate pain $\left(r_{s}=0.29\right.$ and $r_{s}=0.20$ respectively, $p>0.05$ ).

\section{DISCUSSION}

In the current pilot study, we tested for sexassociated psychophysical response differences to thermal stimuli in communicative patients with AD. Our primary predictions were that, relative to males with moderate $\mathrm{AD}$, females with moderate $\mathrm{AD}$ would be more sensitive to thermal pain and report greater pain unpleasantness at all percepts. These predictions were partially supported. While females generally had a lower mild and moderate thermal pain threshold, males reported these same percepts to be more unpleasant. 
Our finding that females with AD had generally lower thermal pain thresholds is consistent with prior literature regarding sex differences in healthy young and older adults $[13,14]$. Alongside psychosocial and cultural considerations, a variety of biologic factors are thought to contribute to heightened sensitivity to pain in females, including sex hormones [26] and differential engagement of cortical and subcortical systems involved in endogenous pain modulation and self-evaluation/awareness [27-29]. For example, a prior study by our group showed less pain-related deactivation of structures in the so-called default mode network in cognitively intact older females, relative to males [28], which in the context of pain is thought to be involved in greater attendance to and evaluation of noxious stimuli [30]. The latter could thus lead to subsequently increased detection and identification of nociceptive stimuli in older females.

Findings in the current study further demonstrate that males perceived mild and moderate thermal pain as more unpleasant than did females. This finding contrasts with our initial prediction. However, greater pain unpleasantness in older males with $\mathrm{AD}$ is consistent with recent work that found greater thermal pain unpleasantness in healthy older men, compared to women [28]. It is possible this finding reflects a relatively greater stimulus intensity required for men to report reaching mild and moderate pain. However, sex-related differences in pain processing likely also play a role. Prior studies examining sex differences in pain-related fMRI activation found healthy young and older women showed both greater activation in the rostral/subgenual anterior cingulate cortex and greater connectivity between this structure and periaqueductal gray [27-29]. Further, greater cingulate activation in older women was associated with reductions in pain unpleasantness, compared to older men [28]. Therefore, increased pain unpleasantness in older males with or without $\mathrm{AD}$ may reflect sex-specific effects of aging on affective and antinociceptive pain pathways.

This study has several strengths. It is the first study to examine and report sex differences in the psychophysical response to experimental thermal pain in people with AD. As such, the study adds to our limited knowledge about factors potentially influencing pain self-reports in verbally communicative $\mathrm{AD}$ patients with up to moderate cognitive impairment. The current study's sample size was modest, consisting of 14 females and 14 males with AD matched for age and cognitive status. However, our findings are strengthened by rigorous subject matching, attention to inclusion and exclusion criteria, and control for potential confounds such as daily pain. The parent study through which the current data were derived was powered to detect differences in pain in people with AD versus healthy controls. Thus, a further limitation is that generalizability of our findings is limited to the study sample. Another potential limitation was the cross-sectional study design, which did not allow for examination of causality or directionality of associations between variables of interest. Since this was a perceptually matched paradigm, the absence of a condition in which both sexes experienced the same supra-threshold pain stimulus temperature also limited ability to interpret the unanticipated pattern of findings regarding affective pain responses.

\section{Conclusions}

Current results suggest that further examination of sex differences in pain experience, pain processing, and even analgesic responses in the context of AD would be worthwhile. Here we show that older individuals with $\mathrm{AD}$ do show sex differences for psychophysical thermal pain responses; while females with AD showed increased thermal pain sensitivity, males rated thermal pain as more unpleasant. These sex differences are consistent with prior studies of pain-related sex differences in healthy older adults. Future work should involve attempts to replicate these findings, for example, with different stimulus modalities, and elucidate a neural mechanism underlying pain-related sex differences in AD. Improved understanding therein could provide a means for more targeted and effective pain assessment and management strategies in older adults with AD.

\section{ACKNOWLEDGMENTS}

The authors would like to thank Robert Anthony, Alison Anderson, and Jessica Harbison for their assistance in preparing this manuscript.

This work was supported by the John A. Hartford Foundation, Mayday Fund, Vanderbilt Office of Clinical and Translational Scientist Development, Vanderbilt Clinical and Translational Research Scholars Program, and the National Institutes of Health National Institute on Aging [grants number K23 AG046379-01A1 and number R21 AG04573501A1]. The contents are solely the responsibility of the authors and do not necessarily represent the official views of these institutions. Study data were 
collected and managed using REDCap electronic data capture tools hosted at Vanderbilt University. REDCap is maintained by Vanderbilt Institute for Clinical and Translational Research which is supported by the National Institutes of Health National Center for Advancing Translational Sciences [grant number UL1 TR000011].

Authors' disclosures available online (http://j-alz. com/manuscript-disclosures/17-0532r1).

\section{AVAILABILITY OF ORIGINAL DATA}

The original raw psychophysical dataset $(\mathrm{N}=80)$ from which the current sample was comprised is available on-line at: https://bmcmedicine.biomed central.com/articles/10.1186/s12916-016-0619-1.

\section{REFERENCES}

[1] Alzheimer's Association, Alzheimer's Disease Facts and Figures, https://www.alz.org/documents_custom/2016facts-and-figures.pdf, Accessed November 6, 2016.

[2] Hadjistavropoulos T, Herr K, Turk DC, Fine PG, Dworkin RH, Helme R, Jackson K, Parmelee PA, Rudy TE, Lynn Beattie B, Chibnall JT, Craig KD, Ferrell B, Ferrell B, Fillingim RB, Gagliese L, Gallagher R, Gibson SJ, Harrison EL, Katz B, Keefe FJ, Lieber SJ, Lussier D, Schmader KE, Tait RC, Weiner DK, Williams J (2007) An interdisciplinary expert consensus statement on assessment of pain in older persons. Clin J Pain 23, S1-S43.

[3] Monroe TB, Misra SK, Habermann RC, Dietrich MS, Cowan RL, Simmons SF (2014) Pain reports and pain medication treatment in nursing home residents with and without dementia. Geriatr Gerontol Int 14, 541-548.

[4] Oosterman JM, Hendriks H, Scott S, Lord K, White N, Sampson EL (2014) When pain memories are lost: A pilot study of semantic knowledge of pain in dementia. Pain Med 15, 751-757.

[5] Hamina A, Taipale H, Tanskanen A, Tolppanen AM, Tiihonen J, Hartikainen S (2017) Differences in analgesic use in community-dwelling persons with and without Alzheimer's disease. Eur J Pain 21, 658-667.

[6] Beach PA, Huck JT, Miranda MM, Bozoki AC (2015) Autonomic, behavioral, and subjective pain responses in Alzheimer's disease. Pain Med 16, 1930-1942.

[7] Beach PA, Huck JT, Miranda MM, Foley KT, Bozoki AC (2016) Effects of Alzheimer's disease on the facial expression of pain. Clin J Pain 32, 478-487.

[8] Kunz M, Scharmann S, Hemmeter U, Schepelmann K, Lautenbacher $S$ (2007) The facial expression of pain in patients with dementia. Pain 133, 221-228.

[9] Cole LJ, Farrell MJ, Duff EP, Barber JB, Egan GF, Gibson SJ (2006) Pain sensitivity and fMRI pain-related brain activity in Alzheimer's disease. Brain 129, 2957-2965.

[10] Monroe TB, Beach PA, Bruehl SP, Dietrich MS, Rogers BP, Gore JC, Atalla SW, Cowan RL (2017) The impact of Alzheimer's disease on the resting state functional connectivity of brain regions modulating pain: A cross sectional study. J Alzheimers Dis 57, 71-83.
[11] Beach PA, Huck J, Zhu D, Bozoki A (2017) Altered behavior and autonomic pain responses in Alzheimer's disease are associated with dysfunctional affective, self-reflective, and salience network resting-state connectivity. Front Aging Neurosci. doi: 10.3389/fnagi.2017.00297

[12] Fillingim RB, King CD, Ribeiro-Dasilva MC, RahimWilliams B, Riley JL 3rd (2009) Sex, gender, and pain: A review of recent clinical and experimental findings. J Pain 10, 447-485.

[13] Bartley EJ, King CD, Sibille KT, Cruz-Almeida Y, Riley JL 3rd, Glover TL, Goodin BR, Sotolongo AS, Herbert MS, Bulls HW, Staud R, Fessler BJ, Redden DT, Bradley LA, Fillingim RB (2016) Enhanced pain sensitivity among individuals with symptomatic knee osteoarthritis: Potential sex differences in central sensitization. Arthritis Care Res (Hoboken) 68, 472-480.

[14] Naugle KM, Ohlman T, Naugle KE, Riley ZA, Keith NR (2017) Physical activity behavior predicts endogenous pain modulation in older adults. Pain 158, 383-390.

[15] Mielke MM, Vemuri P, Rocca WA (2014) Clinical epidemiology of Alzheimer's disease: Assessing sex and gender differences. Clin Epidemiol 6, 37-48.

[16] Folstein MF, Folstein SE, McHugh PR (1975) "Mini-Mental State". A practical method for grading the cognitive state of patients for the clinician. J Psychiatr Res 12, 189-198.

[17] Dubois B, Feldman HH, Jacova C, Dekosky ST, BarbergerGateau P, Cummings J, Delacourte A, Galasko D, Gauthier S, Jicha G, Meguro K, O’Brien J, Pasquier F, Robert P, Rossor M, Salloway S, Stern Y, Visser PJ, Scheltens P (2007) Research criteria for the diagnosis of Alzheimer's disease: Revising the NINCDS-ADRDA criteria. Lancet Neurol 6, 734-746.

[18] Benedetti F, Arduino C, Vighetti S, Asteggiano G, Tarenzi L, Rainero I (2004) Pain reactivity in Alzheimer patients with different degrees of cognitive impairment and brain electrical activity deterioration. Pain 111, 22-29.

[19] Medoc Advanced Medical Systems (2006) Medoc Ltd. Advanced Medical Systems, Durham, NC.

[20] Bair MJ, Wu J, Damush TM, Sutherland JM, Kroenke K (2008) Association of depression and anxiety alone and in combination with chronic musculoskeletal pain in primary care patients. Psychosom Med 70, 890-897.

[21] Friedman B, Heisel MJ, Delavan RL (2005) Psychometric properties of the 15-item Geriatric Depression Scale in functionally impaired, cognitively intact, community-dwelling elderly primary care patients. J Am Geriatr Soc 53, 15701576.

[22] Marc LG, Raue PJ, Bruce ML (2008) Screening performance of the 15-item geriatric depression scale in a diverse elderly home care population. Am J Geriatr Psychiatry 16, 914-921.

[23] Spielberger R, Gorsuch R, Lushene R (1970) The State-Trait Anxiety Inventory (test manual). Consulting Psychologists, Palo Alto, CA.

[24] Cleeland CS, Ryan KM (1994) Pain assessment: Global use of the Brief Pain Inventory. Ann Acad Med Singapore 23, 129-138.

[25] Weiner D, Peterson B, Keefe F (1999) Chronic painassociated behaviors in the nursing home: Resident versus caregiver perceptions. Pain 80, 577-588.

[26] Farmer MA, Leja A, Foxen-Craft E, Chan L, MacIntyre LC, Niaki T, Chen M, Mapplebeck JC, Tabry V, Topham L, Sukosd M, Binik YM, Pfaus JG, Mogil JS (2014) Pain reduces sexual motivation in female but not male mice. J Neurosci 34, 5747-5753. 
[27] Monroe TB, Fillingim RB, Bruehl SP, Rogers BP, Dietrich MS, Gore JC, Atalla SW, Cowan RL (2017) Sex differences in brain regions modulating pain among older adults: A cross-sectional resting state functional connectivity study. Pain Med. doi: 10.1093/pm/pnx084

[28] Monroe TB, Gore JC, Bruehl SP, Benningfield MM, Dietrich MS, Chen LM, Newhouse P, Fillingim R, Chodkowski B, Atalla S, Arrieta J, Damon SM, Blackford JU, Cowan RL (2015) Sex differences in psychophysical and neurophysio- logical responses to pain in older adults: A cross-sectional study. Biol Sex Differ 6, 25.

[29] Wang G, Erpelding N, Davis KD (2014) Sex differences in connectivity of the subgenual anterior cingulate cortex. Pain 155, 755-763.

[30] Kong J, Loggia ML, Zyloney C, Tu P, Laviolette P, Gollub RL (2010) Exploring the brain in pain: Activations, deactivations and their relation. Pain 148, 257-267. 